\title{
TECNOLOGÍAS DE LA INFORMACIÓN Y LA \\ COMUNICACIÓN EN LOS ESTUDIOS A DISTANCIA DE LAS \\ UNIVERSIDADES PRIVADAS DEL \\ MUNICIPIO MARACAIBO - VENEZUELA
}

\section{THE INFORMATION AND COMMUNICATION \\ TECHNOLOGIES IN DISTANCE EDUCATION \\ OF PRIVATE UNIVERSITIES IN \\ MARACAIBO MUNICIPALITY - VENEZUELA}

\begin{abstract}
AUTORES
Pablo Miguel Garcés Briceño: Centro de Investigación de Humanidades y Educación (CIHE).

Universidad Rafael Belloso Chacín. Maracaibo (Venezuela).

pablogarcespmgb@gmail.com

Francisco Adolfo Batlle Rois-Méndez: Centro de Investigación de Humanidades y Educación (CIHE). Universidad Rafael Belloso Chacín. Maracaibo (Venezuela).

francisco.batlle@urbe.edu
\end{abstract}

\section{RESUMEN}

La investigación se realizó con el propósito de analizar las Tecnologías de la Información y la Comunicación utilizadas en los estudios a distancia de las universidades privadas del Municipio Maracaibo, estado Zulia, Venezuela. Para ello se revisaron los postulados de (Camargo, 2008), (Rietveldt y Neuman, 2008), (Cabero, 2007), (Rosario, 2005), (Van-Der Hofstadt, 2005), (Fournier, 2004), (Cascón, 2004) y (Alarico, 2001), entre otros, en relación con las Tecnologías de la Información y la 
Comunicación. El estudio fue de tipo descriptivo con un diseño de campo, no experimental-transeccional. La población estuvo constituida por 14 sujetos identificados como directores y coordinadores de estudios a distancia de las universidades privadas del Municipio Maracaibo. El censo poblacional fue utilizado debido al reducido tamaño de la muestra. Para la recolección de datos, se aplicó un instrumento con escala Likert de 60 ítemes el cual fue sometido a la validez de contenido a través del juicio de cinco expertos, y se midió su confiabilidad aplicando el coeficiente alfa cronbach, la cual fue muy alta $(0,93)$. Los resultados se analizaron según un baremo previamente establecido. Se pudo concluir que existe un uso adecuado de las Tecnologías de la Información y la Comunicación utilizadas en los estudios a distancia. Por otra parte, se concluyó que existen ciertas bondades presentes en dichas tecnologías que no están siendo aprovechadas para maximizar la efectividad del proceso de comunicación.

\section{PALABRAS CLAVE}

Tecnologías - Comunicación - Estudios a Distancia.

\section{ABSTRACT}

The investigation was made in order to analyze the Information and Communication Technologies in Distance Education of Private Universities in Maracaibo Municipality, Zulia state, Venezuela. (Camargo, 2008), (Rietveldt y Neuman, 2008), (Cabero, 2007), (Rosario, 2005), (Van-Der Hofstadt, 2005), (Fournier, 2004), (Cascón, 2004) and (Alarico, 2001), among others, regarding the Information and Communication Technologies. The study was descriptive type with a design of field, nonexperimental-transectional. The sample was constituted by 14 subjects identified as directors and coordinators of distance education of private universities in Maracaibo. The population census was used due to the reduced size of the sample. In order to collect the information, a survey 
with a Likert scale of 60 items was applied which was put under the validity of content through judgment of five experts, and its reliability was measured applying the alpha cronbach coefficient, which was very high $(0,93)$. The results were analyzed according to a scale previously established. It was possible to be concluded that there is an adequate use of the information and communication technologies used in distance education. In the other hand, it was concluded that there are certain benefits in the technologies mentioned, which advantages aren't been taken to maximize the effectiveness in the communication process.

\section{KEY WORDS}

Technologies - Communication - Distance Education.

\section{ÍNDICE}

$\boldsymbol{\sim}$ 1. INTRODUCCIÓN

$\boldsymbol{\sim}$ 2. LAS TECNOLOGÍAS DE LA INFORMACIÓN Y LA COMUNICACIÓN

2.1. Elementos Estructurales de la Comunicación

…ำ 2.1.1. Emisor

.7.1.2. Receptor

뜬 2.1.3. Mensaje

2.1.4. Canal

ar. 2.1.5. Código

. 2.1.6. Retroalimentación

in 2.1.7. Escucha activa

[a 2.1.8. Ruido

2.2. Características de las Tecnologías de la Información y la Comunicación

[n 2.2.1. Inmaterialidad

2.2.2. Interconexión 
añ 2.2.3. Interactividad

. 2.2.4. Instantaneidad

‥' 2.2.5. Digitalización

2.2.6. Diversidad

2.2.7. Innovación

2.2.8. Multimedialidad

2.3. Condiciones de los Procesos Mediados por las Tecnologías de la Información y la Comunicación

2.3.1. Condición virtual

a 2.3.2. Condición interactiva

2.3.3. Condición asincrónica

1. 2.3.4. Condición hipermediática

$\boldsymbol{\sim}$ 3. ASPECTOS METODOLÓGICOS

$\boldsymbol{\sim}$ 4. RESULTADOS

5. LINEAMIENTOS

6. CONCLUSIONES

7. REFERENCIAS BIBLIOGRÁFICAS

\section{INTRODUCCIÓN}

Convivir con la tecnología es parte de la cotidianeidad de la civilización moderna. Los procesos humanos tienden a complementarse con ella, dándole provecho a las ventajas que pueden ofrecer en los diversos ámbitos en los cuales son aplicados. Inclusive, en muchos casos, dichos procesos llegan a depender de la tecnología.

Un proceso enormemente beneficiado por el uso de la tecnología es, sin duda, la comunicación, que se ha valido de sus bondades para evolucionar en nuevas formas, fieles y veloces, de contacto humano, mediante el cual se han reducido las barreras 
comunicacionales que siempre han sido representadas por elementos como la distancia, entre otros.

Surgen, las Tecnologías de la Información y la Comunicación para dar explicación al amplio espectro tecnológico que ha sido predominantemente utilizado para manejar información y entablar procesos comunicativos entre los seres que las utilizan, maximizando las características de dichos procesos.

Uno de los ámbitos de la actualidad que dependen en su totalidad de la utilización de estas tecnologías son los estudios a distancia, en los cuales se producen procesos de comunicación constantemente y se presume la existencia de una falta de aprovechamiento de las bondades que estas ofrecen.

En referencia a ello, (Cabero, 2002) manifiesta que la cultura actual demanda recibir la información en las mejores condiciones técnicas posibles y en el menor tiempo permitido. Esto significa que no sólo es importante comunicar por medio de las TIC, también es necesario hacerlo en la forma más cómoda posible.

El hecho de que estas ventajas existan, no significa que sean aplicadas en todas las partes del mundo o en todos los contextos de la humanidad. Un ejemplo es el de las tecnologías de la información y la comunicación en la educación: uno de los problemas en el contexto educativo es que a pesar de lo que pueden tolerar las tecnologías, es poco lo introducido que permita una interacción sujeto-máquina y su adaptación a las características educativas de las personas.

Este problema implica, según el autor precitado, que la característica de interactividad presente en las TIC, no está siendo aprovechada por sus usuarios en el contexto educacional, o bien, no se está explotando su potencial. De este modo, las mismas 
permiten que las personas no sean simplemente receptores pasivos sino que también se vuelvan activos.

En Venezuela el caso no es diferente; la sociedad conoce ampliamente el potencial de la tecnología y puede determinar en qué porción no está siendo beneficiada por ella. A los estudiantes de distintos niveles de la educación se les puede ofrecer un proceso de aprendizaje mediante tecnología interactiva, instantánea e innovadora, que rompe con la linealidad del sistema tradicional, gracias a las características inherentes a las TIC ofrecen.

La educación en el país parece apuntar hacia la digitalización de la información. Sin embargo, (Camargo, 2008) indica que, en su mayoría, los mensajes emitidos por las TIC no están siendo propiamente decodificados por los alumnos en la educación venezolana. El motivo puede no estar completamente determinado, pero es de considerarse parte del problema.

Dentro de este ámbito, los estudios a distancia, mediante entornos virtuales, surgen para atender otra demanda social. En este contexto, las tecnologías juegan el papel primordial en el procedimiento de aprendizaje, debido a sus condiciones presentes en la mediación de procesos, las cuales determinan su enorme potencialidad comunicacional para la educación.

Al abordar dichas condiciones, se puede estudiar la potencialidad comunicacional a la cual se hizo referencia con anterioridad, para determinar en qué medida está siendo aprovechada en la educación venezolana. Sin embargo, existen otros aspectos altamente determinantes que afectan esta relación entre potencial y necesidad. 
Al llevar este análisis a las universidades privadas del Municipio Maracaibo, que ofrecen estudios a distancia, y basado en la observación no sistemática del investigador, se presume que, a pesar de que el uso de las tecnologías de la información y la comunicación es amplio, su máximo potencial comunicacional no es aprovechado.

Una de las posibles causas podría radicar en el hecho de que ciertas instituciones de educación superior posean, o no, la capacidad tecnológica para poder soportar las exigencias técnicas de algunas de las herramientas comunicacionales. Igualmente, se puede considerar si existe dentro de la institución de un laboratorio único para docentes de educación a distancia con todas las unidades provistas de cámaras Web y equipos de audio, así como procesadores capaces de soportar altas velocidades de Internet.

Asimismo, se ha podido observar que, a pesar de que en los estudios a distancia se pueden ofrecer herramientas tecnológicas como el blog, la pizarra compartida, audio y video conferencia; los cursos se limitan a utilizar una plataforma para compartir archivos, chat y foros. Herramientas obviadas que representan en sí altos niveles de potencialidad comunicacional en el proceso de aprendizaje.

En relación a lo anteriormente expuesto, se considera, que el potencial comunicacional de las TIC, aplicadas a la educación, son parte importante del proceso de aprendizaje en entornos virtuales y en él pudiese no estarse aprovechando las ventajas ofrecidas por las herramientas comunicacionales. Esto afecta directamente el proceso generación de conocimiento, que si bien, no imposibilita que ocurra, desaprovecha su capacidad de mejores resultados.

Es por ello que se hace necesario llevar a cabo una investigación que tenga la capacidad de analizar la forma en la cual son utilizadas las tecnologías de información y comunicación en los estudios a distancia. Para ello se estableció como objetivo general: 
analizar las tecnologías de la información y la comunicación utilizadas en los estudios a distancia de las universidades privadas del Municipio Maracaibo; el cual fue alcanzando midiendo los siguientes objetivos específicos: (a) identificar los elementos estructurales de la comunicación considerados en los estudios a distancia de las universidades privadas del Municipio Maracaibo; (b) describir las características de las tecnologías de la información y la comunicación utilizadas en los estudios a distancia de las universidades privadas del Municipio Maracaibo, (c) analizar las condiciones de los procesos mediados por las tecnologías de la información y la comunicación aplicadas en los estudios a distancia de las universidades privadas del Municipio Maracaibo, y (d) proponer lineamientos para la optimización del uso de las herramientas comunicacionales en las Tecnologías de la información y la comunicación utilizadas en los estudios a distancia de las universidades privadas del Municipio Maracaibo.

\section{LAS TECNOLOGÍAS DE LA INFORMACIÓN Y LA COMUNICACIÓN}

En primera instancia, se hace necesario definir lo que son las Tecnologías de la Información y la Comunicación, las cuales son denominadas por (Rosario, 2005) como el total de tecnologías mediante las cuales es posible la adquirir, producir, almacenar, tratar, comunicar, registrar y presentar informaciones, en forma de voz, imágenes y datos codificados en señales acústicas, ópticas o electromagnéticas.

A su vez, en la Conferencia de Autoridades Iberoamericanas de Informática (CAIBI, 2001) citado por Observatorio para la Sociedad de la Información en Latinoamérica y el Caribe (OSILAC, 2004) se manifiesta que las Tecnologías de la Información y la Comunicación consisten en la conversión tecnológica entre las telecomunicaciones, la computación, la microelectrónica y el manejo de la información. Agregándole a ello que poseen como sus componentes el hardware, el software, los servicios y las telecomunicaciones. 
Con base en lo anteriormente expuesto se considera pertinente la definición de (Rosario, 2005) la cual menciona las posibles acciones que se relacionan con el uso de las Tecnologías de la Información y la Comunicación, ya que, partiendo de estas es posible estudiar el potencial que poseen, lo cual es pertinente para la presente investigación.

\subsection{Elementos estructurales de la comunicación}

Según indica (Fournier, 2004), Aristóteles fue el primero en determinar los elementos que estructuran a la comunicación, en un modelo sencillo que únicamente incluía al emisor, al receptor y al mensaje. Con el avance de los estudios, se han agregado más elementos que han complementado la estructura y se ha creado un esquema adecuado que permite comprender todo el proceso.

El autor previamente citado indicó que los elementos que estructuran la comunicación son los siguientes:

\subsubsection{Emisor}

(Fournier, 2004) define al emisor como aquel actor que codifica un mensaje y lo envía, expresado a través de un código. El proceso de comunicación parte del mismo y de su conocimiento y experiencias. Para que este procedimiento pueda concretarse, el mismo, debe poseer las habilidades comunicativas de hablar y escribir.

Por otra parte, (Alonso, 2006:126) al estudiar al emisor en el contexto de las Tecnologías de la Información y la Comunicación afirma que "en la comunicación virtual podemos hablar de la existencia de un emisor múltiple, en el momento en que las condiciones de la propia tecnología posibilitan que cualquier sujeto o grupo pueda constituirse en productor de mensajes". 


\subsubsection{Receptor}

A su vez, (Fournier, 2004) manifiesta que el receptor es aquel que decodifica un mensaje al recibirlo, en concordancia con el código del emisor. De la misma manera debe poseer las habilidades comunicativas que le permitan decodificar el mensaje de forma fácil. Estas habilidades son las del escuchar y leer.

En contraste, (Van-Der Hofstadt, 2005) define al emisor, no solamente como el individuo dentro del proceso comunicativo que recibe el mensaje, sino también, como aquel a quien el mensaje va dirigido, destacando el hecho de que realmente no es necesaria la presencia del receptor en el mismo espacio y que la respuesta que el mismo dé, no requiere ser instantánea.

\subsubsection{Mensaje}

De igual manera, (Fournier, 2004) plantea que el mensaje es el contenido de información que se desea transmitir y que es expresado mediante un código. Cabe destacar que el mensaje es transmitido desde el emisor hasta el receptor por medio de un canal.

Así mismo, (Van-Der Hofstadt, 2005:10), expone que el mensaje es "el conjunto de las diferentes ideas o informaciones que se transmiten mediante códigos, claves, imágenes, etc.". También agrega que el término al que se hizo referencia con anterioridad consta de la idea que se desea transmitir y todo aquello que lo rodea, lo cual tiene la función de facilitar la comprensión del mismo.

\subsubsection{Canal}

Igualmente, el canal es definido por (Fournier, 2004:41) como "el medio por el cual se transmite el mensaje". Agrega que en la comunicación humana existen, básicamente, dos tipos de canal. Uno, proveniente de las cualidades fisiológicas o naturales de los seres humanos, que se manifiestan por medio de los sentidos, y el otro, que es resultado 
de las creaciones tecnológicas o artificiales y que están representados por los medios masivos de comunicación.

Por otra parte, (Van-Der Hofstadt, 2005:11) manifiesta que el canal es "el medio mediante el cual se emite el mensaje del emisor al receptor. Supone el soporte de la información que actúa como línea de transmisión". También hace referencia a la comunicación interpersonal en la cual se utilizan canales de carácter oral-auditivo y gráfico visual.

\subsubsection{Código}

(Fournier, 2004:40) explica que el código es "el sistema de signos empleados para expresar el mensaje". Destaca que debe ser común entre el emisor y el receptor, o de lo contrario, el proceso de comunicación se verá afectado. Agrega que "estos signos pueden ser orales, escritos, cromáticos, icónicos, sónicos, entre muchos otros".

En contraste, (Alarico, 2001) indica que el código es el conjunto de símbolos en cualquier contexto que ostenta la posibilidad de ser estructurado de forma que su contenido represente un significado para un individuo. Acota que el código debe ser igual entre los individuos envueltos en el proceso de comunicación para que el mismo sea posible.

\subsubsection{Retroalimentación}

Sobre la característica de la retroalimentación, (Fournier, 2004:143) explica que "es la respuesta por parte del receptor acerca de la información recibida. No hay comunicación cuando el emisor no se entera de cuál es la respuesta a su mensaje". Es decir, que solo al existir retroalimentación se completa el proceso de comunicación. En el caso contrario, solo se habrá dado difusión de información. A este ciclo el autor precitado lo denomina "circuito del habla". 
Del concepto referido, (Van-Der Hofstadt, 2005:12) señala que en el contexto comunicacional, la retroalimentación "supone la información que devuelve el receptor al emisor sobre su propia comunicación, tanto en lo que refiere a su contenido como a la interpretación del mismo o sus consecuencias en el comportamiento de los interlocutores"

\subsubsection{Escucha activa}

El concepto de escucha activa, se define según (Van-der Hofstadt, 2005:77) como “Esfuerzo físico y mental de querer escuchar con atención la totalidad del mensaje que se emite, tratando de interpretar el significado correcto del mismo, a través del comunicado verbal y no verbal que realiza el emisor", igualmente agrega, que en este proceso se utiliza la retroalimentación para indicar lo que se cree estar entendiendo.

Sin embargo, (Rulicky y Cherny, 2007) conceptualizan el término de escucha activa como la acción del receptor de manifestar interés en relación a aquello que está siendo expuesto por el interlocutor, mediante comunicación de carácter verbal o no verbal, que funciona como motor de empatía.

Dicho concepto suele considerarse una característica del habla en persona, ya que, en la mayoría de las ocasiones se requiere presencia física para demostrar reacciones físicas y verbales ante los mensajes recibidos.

\subsubsection{Ruido}

El concepto de ruido está definido por (Fournier, 2004:144) como “la interrupción u obstáculo que impide una comunicación efectiva", también lo identifica como interferencia. Del mismo modo, el autor precitado indica que se puede dar en cualquier punto del proceso de comunicación, como el emisor, el receptor y el canal, entre otros; y que puede ser: físico, fisiológico, psicológico, semántico y técnico. 
Por otra parte, (Van-Der Hofstadt, 2005:11), en referencia al concepto, indica que "son todas la alteraciones que se producen durante la transmisión del mensaje". Incluye ejemplos como: dificultades en el sonido o la recepción, interrupciones visuales, etc. y que evitarlas minimiza el "efecto negativo sobre el proceso de comunicación".

\subsection{Características de las tecnologías de la información y la comunicación}

Las Tecnologías de la Información y la Comunicación presentan una serie de características que le acreditan sus principales condiciones y ventajas dentro de cualquier ámbito en donde se apliquen. (Cabero, 2007) indica que estas características son conocidas como:

\subsubsection{Inmaterialidad}

De acuerdo al concepto de (Cabero, 2007), la inmaterialidad implica que, en el proceso en el cual se desarrolla su actividad, no existe materia prima física como tal. La misma, se reconoce en la forma de información y se presenta en formas visuales, o en una combinación de ellas, así como también, puede ser estacionaria o en movimiento.

A su vez, (Rosario, 2005) indica que las Tecnologías de la Información y la Comunicación pueden transformar la información, que de forma tradicional se considera atada a un componente físico, a algo inmaterial. También agrega que la data se puede transferir desde dispositivos electrónicos lejanos mediante redes de comunicación de forma absolutamente inmaterial. Explica que ésta característica es la que produce la existencia de la realidad no real o realidad virtual. 


\subsubsection{Interconexión}

Según (Cabero, 2007), las Tecnologías de la Información y la Comunicación presentan de forma individual una extensa cantidad de ventajas, y aunado a ello, la posibilidad de combinarse entre sí, ocasionando una multiplicación de las mismas, como por ejemplo, la combinación de la televisión por cable con la satelital. De este modo, existen conexiones mediante las cuales se construyen realidades expresivas y comunicativas, como ocurre al combinar imagen, sonido y texto para armar las plataformas multimedia.

\subsubsection{Interactividad}

(Cabero, 2007) define la interactividad como aquella capacidad existente en las Tecnologías de la Información y la Comunicación para producir un desplazamiento efectivo del control de dicha comunicación hacia el receptor, considerando que en los métodos tradicionales, se encuentra únicamente en el emisor.

En contraste, (Rosario, 2005) explica que dicho concepto consiste en la comunicación bidireccional, sincrónica o asincrónica, que se da entre personas y/o grupos que establecen una comunicación mediante tecnologías. Destaca que el individuo que hace uso de las Tecnologías de la Información y la Comunicación es un sujeto activo con la capacidad de enviar sus propios mensajes y tomar decisiones sobre los procesos que lleva como la secuencia, el ritmo y el código entre otros.

\subsubsection{Instantaneidad}

En su estudio, (Cabero, 2007) determina que la instantaneidad es una de las principales características de las Tecnologías de la Información y la Comunicación ya que destruye todas las posibles barreras espaciales que se pueden dar en el proceso comunicativo, permitiendo que se establezcan diversos tipos de comunicaciones entre distancias virtualmente infinitas, en periodos de tiempo mínimos. Esta característica se expande 
conforme exista mayor acceso a tecnologías avanzadas desde el chat hasta la videoconferencia.

Igualmente, (Rosario, 2005) agrega que la característica previamente mencionada significa que la información puede ser transmitida de manera inmediata entre lugares que se encuentren físicamente alejados, y que las vías virtuales mediante las cuales éste fenómeno se da están denominadas como autopistas de la información.

\subsubsection{Digitalización}

(Cabero, 2007) manifiesta que los avances en la tecnología actual, han permitido la transformación de la información a formatos inmateriales que pueden transferirse por medio de redes comunicacionales y a dispositivos físicos de tamaño reducido como el hardrive, el Compact Disc o el pendrive, también conocido como hardware.

Del mismo modo, (Rosario, 2005) explica que la digitalización surge como consecuencia de otra característica de las Tecnologías de la Información y la Comunicación denominada inmaterialidad, y que a causa de ello se ha podido dar la aparición de nuevos soportes como el magnético y el óptico con lo cual se ha pasado desde el lápiz y el papel hasta el teclado y la pantalla, además de la transmisión de información en espectros inmateriales como la realidad virtual.

\subsubsection{Diversidad}

A su vez, las Tecnologías de la Información y la Comunicación presentan la característica de la diversidad en la cual (Cabero, 2007:13) afirma que "no existe una única tecnología disponible si no que, por el contrario, se tiene una variedad de ellas, que pueden desempeñar diferentes funciones", y estas giran alrededor de todas la características ya indicadas con anterioridad. 


\subsubsection{Innovación}

Cabe destacar, que las Tecnologías de la Información y la Comunicación, en la actualidad, tienen la capacidad de hacer cosas que hace poco tiempo eran inimaginables, como expresa (Cabero, 2007). Esto demuestra la característica innovadora presente en ella, en la cual, evoluciona de forma progresiva y rápida.

La vigencia de las novedades tecnológicas tiende a ser corta ya que constantemente son superadas por nuevos hallazgos desarrollados por medio de las investigaciones científicas y los avances en el mundo de la computación y la informática. En teoría, lo nuevo deja de serlo en periodos de tiempo relativamente cortos.

De esta manera, las herramientas disponibles para los usuarios de las tecnologías mejoran progresivamente su rendimiento con actualizaciones de carácter físico e informático, consecuentemente aportando mejoras el proceso de comunicación que se encuentran mediando, y que gradualmente se acopla a las mismas.

Un ejemplo de este proceso de innovación es la Realidad Aumentada. (Heras y Villarreal, 2004:4) explican que consiste en "una tecnología que integra señales captadas del mundo real (típicamente video y audio) con señales generadas por computadores (objetos gráficos tridimensionales); las hace corresponder para construir nuevos mundos coherentes, complementados y enriquecidos".

\subsubsection{Multimedialidad}

Es definida por (Cabero, 2007) como la "Implementación y complementariedad de los formatos en un mismo mensaje". Explica que los medios utilizados en las Tecnologías de la Información y la Comunicación no son excluyentes entre sí, si no por el contrario, pueden funcionar complementándose. 
Por otra parte, (Rosario, 2005), con respecto a este concepto, manifiesta que contribuye en el desarrollo de la tecnología, ya que mediante el mismo, es posible unificar imágenes en movimiento y sonido con una integración de secuencialidad diacrónica con la representación espacial sincrónica de las imágenes.

\subsection{Condiciones de los procesos mediados por las tecnologías de la información y la comunicación.}

Es posible visualizar cómo ciertos procesos en la actualidad son mediados por las Tecnologías de la Información y la Comunicación. Las características sobre las cuales se reflexionó con anterioridad traen como consecuencia que dichos procesos ocurran bajo determinadas condiciones. Según (Rietveldt y Neuman, 2008), estos procesos se encuentran sujetos a las siguientes condiciones:

\subsubsection{Condición virtual}

(Rietveldt y Neuman, 2008:5) explican que "La comunicación sucede en un "espacio" digital por la trasmisión de información en código binario". Aunado a lo anteriormente expuesto, los autores explican que a pesar de que ese "espacio" en donde la persona se encuentra, reside en el computador y se estructura con elementos de carácter visual y auditivo, realmente no existe como tal, sino que es un código binario recibido por el computador mediante impulsos eléctricos y transformados en una información comprensible para el ser humano.

Igualmente, (García, Domínguez y Ruiz, 2007) manifiestan que las tecnologías permiten que el ambiente mediante el cual se produce el proceso de comunicación no sea real, y que ni los elementos, ni las acciones en el contexto, sean materiales. Los autores coinciden al indicar que el entorno virtual de la comunicación en los estudios a 
distancia está compuesto por un ambiente físicamente inexistente, constituido por elementos inmateriales.

\subsubsection{Condición interactiva}

Como se mencionó con anterioridad en la presente investigación, las Tecnologías de la Información y la Comunicación poseen la característica de ser interactivas. Dicha cualidad condiciona el proceso comunicativo mediado a través de ellas bajo la misma característica. (Stokes, 2004) manifiesta que en el proceso comunicativo dado mediante estas tecnologías se da un "intercambio abierto y fluido de información entre personas en línea".

Por otra parte, el concepto no abarca únicamente el flujo de la información, sino también el rol de los actores dentro del proceso comunicativo. (Rietveldt y Neuman, 2008:6) explican que esta condición "hace posible que los emisores y receptores de un mensaje alternen sus roles en tiempo real para lograr una verdadera comunicación y no flujos informativos unidireccionales".

\subsubsection{Condición asincrónica}

(Vignolles, 2006:1) define la sincronización temporal, contrastándola con la asincronización, indicando que "la comunicación sincrónica se desarrolla en tiempo real; la asincrónica se desarrolla en tiempo diferido y es necesario un lapso temporal entre la emisión y la recepción del mensaje".

En este mismo orden de ideas, (Cabero, Llorente y Román, 2004) indican que son sincrónicas las herramientas de comunicación tales como: el chat, el TV web o videostreaming, la videoconferencia, audioconferencia, entre otros. Es decir, cada mensaje transmitido mediante estas diversas tecnologías funcionará de forma efectiva, siempre y 
cuando, exista una coordinación sincrónica entre el emisor, el receptor y la herramienta utilizada.

\subsubsection{Condición hipermediática}

(Cely, 2004) define a la condición hipermediática como la circunstancia de las Tecnologías de la Información y la Comunicación en la cual se combinan el hipertexto y la multimedia, originando así la combinación de ideas y conceptos a través de redes de información virtuales mediante los cuales un individuo de puede desplazar.

El principio de hipermedialidad según (Rietveldt y Neuman, 2008) parte del hecho de que el ser humano no piensa de forma lineal, como se le ha obligado a manejar información con los métodos de comunicación que son secuenciales, tradicionales. Éstos se consideran lineales por sus parámetros de asimilación, como el texto impreso que debe leerse de izquierda a derecha y de arriba hacia abajo, o la televisión que se ve aprecia una secuencia lineal de tiempo que va desde un principio hasta un fin.

\section{ASPECTOS METODOLÓGICOS}

La investigación fue descriptiva, ya que se describieron las características del proceso mediante el cual se utilizan las Tecnologías de la Información y la Comunicación dentro de la educación a distancia y para ello se recaudó toda la información posible con respecto a la variable, sus dimensiones e indicadores.

El estudio tuvo un diseño de campo porque la información se tomó directamente de la realidad. Así mismo, fue no experimental, ya que sólo se estudió la situación en las condiciones en la que se encuentra actualmente. Por último, el diseño de la investigación también fue transeccional, cuya condición es definida por el momento de recolección de datos y análisis, ya que los mismos se dieron en un momento único. 
La población estuvo compuesta por 14 sujetos, directores y coordinadores de los departamentos de estudios a distancia existentes en las universidades privadas del Municipio Maracaibo, siendo estas: la Universidad Rafael Belloso Chacín y la Universidad Católica Cecilio Acosta.

Para la recolección de datos se utilizó la técnica de la encuesta y como instrumento, un cuestionario con escalamiento Likert, el cual fue validado por cinco expertos y al cual se le midió la confiabilidad, a través del cálculo del estadístico Alfa Cronbach, resultando muy alta $(0,93)$. Las medias aritméticas de los indicadores, dimensiones y variables fueron categorizadas según un baremo previamente establecido que se construyó con base en los intervalos que ofrecen las alternativas de respuesta planteadas en cada instrumento.

Baremo ponderado para la categorización de los promedios de la variable Tecnologías de la Información y la Comunicación, sus dimensiones e indicadores

\begin{tabular}{|c|c|}
\hline Categoría & Rango \\
\hline Poca Presencia & $1.00 \leq x<2.33$ \\
\hline Media Presencia & $2.33 \leq x<3.66$ \\
\hline Alta Presencia & $3.66 \leq x<5.00$ \\
\hline
\end{tabular}

\section{RESULTADOS}

Una vez analizados los resultados se procedió a calcular, mediante la Estadística Descriptiva, la media aritmética de los puntajes correspondientes a los indicadores, las dimensiones y las variables con el objeto de obtener el apoyo estadístico necesario y pertinente para confrontar los resultados con las teorías que sustentaron la 
investigación, a la vez que se categorizaron según el baremo ponderado diseñado para tal fin.

\section{Tabla 1}

Distribución de Medias Aritméticas de los Indicadores de la Dimensión Elementos Estructurales de la Comunicación de la Variable Tecnologías de la Información y la Comunicación

\begin{tabular}{|l|c|c|c|c|c|c|c|c|}
\hline DIMENSIÓN & \multicolumn{7}{|c|}{ Elementos Estructurales de la Comunicación } \\
\hline INDICADORES & EMISOR & RECEPTOR & MENSAJE & CANAL & CÓDIGO & RETRO & $\begin{array}{c}\text { ESC. } \\
\text { AC. }\end{array}$ & RUIDO \\
\hline X Indicador $_{\text {Ind }}$ & 3.90 & 4.10 & 4.02 & 3.62 & 4.31 & 4.10 & 2.29 & 2.79 \\
\hline $\mathbf{X}_{\text {Dimensión }}$ & \multicolumn{10}{|c|}{3.64} \\
\hline
\end{tabular}

En la tabla 1 se observa que la media aritmética del indicador emisor es de 3.90 ubicándolo en la categoría de alta utilización en atención al baremo establecido. Esto coincide con (Alonso, 2006) quien fundamenta que el emisor dentro del proceso comunicacional es aquel que pueda constituirse como productor de mensajes. Del mismo modo, se encuentra en concordancia con lo expuesto por (Fournier, 2004) quien indica las habilidades que debe poseer el emisor para poder serlo.

En consecuencia, en los estudios a distancia de las universidades privadas del Municipio Maracaibo del estado Zulia, los estudiantes y los profesores, mediante entornos virtuales, pueden constituirse como emisores de mensajes. De esta manera, su función como emisor, dentro del proceso comunicativo, se ajusta en una medida adecuada.

Del mismo modo, se contempla que la media aritmética del indicador receptor es de 4.10 ubicándolo en la categoría de alta utilización en atención al baremo establecido. 
Esto se encuentra en concordancia con los planteamientos estipulados por (Fournier, 2004) en donde establece que el receptor decodifica el mensaje recibido adecuado al código del emisor y que, de la misma manera, posee habilidades que le permiten hacerlo.

Consecuentemente, en los estudios a distancia de las universidades privadas del Municipio Maracaibo del estado Zulia, los estudiantes y los profesores, mediante entornos virtuales, pueden constituirse como receptores de mensajes ya que poseen las habilidades para ello y el código en el que lo hacen están en concordancia con el del receptor.

Igualmente, se contempla que la media aritmética del indicador mensaje es de 4.02 ubicándolo en la categoría de alta utilización de acuerdo al baremo establecido. Esto coincide con lo expuesto por (Fournier, 2004), donde explica que el mensaje es el contenido de información que desea ser transmitido. De esta manera, en los estudios a distancia de las universidades privadas del Municipio Maracaibo del estado Zulia, se entabla, de manera efectiva, un proceso de comunicación en el cual existen mensajes que son transmitidos entre individuos dentro de él.

En este mismo orden de ideas, se contempla que la media aritmética del indicador canal es de 3.62 ubicándolo en la categoría de media utilización de acuerdo al baremo establecido. Esto indica que su presencia concuerda medianamente con lo expuesto por (Fournier, 2004) en donde manifiesta que mediante el canal se transmite un mensaje.

Consecuentemente, los estudios a distancia de las universidades privadas del Municipio Maracaibo del estado Zulia, manejan diversos canales a través de los cuales se pueden emitir mensajes. Estos pueden ser el chat, los correos electrónicos e inclusive la comunicación directa. Los mismos, son utilizados con una mediana frecuencia. 
Se observa que la media aritmética del indicador código es de 4.31 ubicándolo en la categoría de alta utilización en atención al baremo establecido. Esta data está en concordancia con lo establecido por (Alarico, 2001) quien manifiesta que el código es un conjunto de símbolos que pueden ser estructurados de forma que su contenido represente un significado. Este concepto debe ser el mismo entre el emisor y el receptor para que ocurra una comunicación efectiva.

Consecuentemente, los estudios a distancia de las universidades privadas del Municipio Maracaibo del estado Zulia, establecen códigos comprensibles entre sus emisores y receptores, empezando por el hecho de hablar el mismo idioma y luego, por el dialecto utilizado en el entorno virtual, en el cual existe una comunicación efectiva en una medida alta.

Por otra parte, la media aritmética del indicador retroalimentación es de 4.10 ubicándolo en la categoría de alta utilización con respecto al baremo establecido. Esto coincide con lo planteado por (Fournier, 2004) en donde establece que la retroalimentación existe cuando el receptor produce una respuesta en relación a la información emitida, y en ella el emisor se entera de la respuesta de su mensaje. Este resultado evidencia que, los estudios a distancia de las universidades privadas del Municipio Maracaibo del estado Zulia, manejan retroalimentación, completando de forma efectiva el proceso de comunicación, cuando cada individuo recibe respuesta de sus mensajes emitidos.

Asimismo, se observa que la media aritmética del indicador escucha activa es de 2.29 ubicándolo en la categoría de baja utilización en atención al baremo establecido. Este resultado no concuerda con lo establecido por (Van-Der Hofstadt, 2005), quien explica que en la escucha activa se demuestra atención al mensaje recibido mediante gestos 
verbales y no-verbales. Como consecuencia de esto, en los estudios a distancia de las universidades privadas del Municipio Maracaibo del estado Zulia, las Tecnologías de la Información y la Comunicación permiten demostrar escucha activa, en una baja medida, al recibir mensajes, a pesar de que ciertas herramientas tecnológicas abren la posibilidad a ello, como por ejemplo: la videoconferencia, video llamada y voz sobre I.P.

Igualmente, la media aritmética del indicador ruido es de 2.79 ubicándolo en la categoría de baja utilización en atención al baremo establecido. Esto se encuentra en concordancia con lo manifestado por (Fournier, 2004) en donde indica que existe ruido al haber una interferencia o interrupción en el proceso de comunicación que altera el proceso, causando que éste no sea efectivo.

Finalmente, en relación con la dimensión Elementos Estructurales de la Comunicación, se observa que la media aritmética es de 3.64 ubicándola en la categoría de media utilización con respecto al baremo establecido. Esto se encuentra medianamente en concordancia con lo expuesto por (Fournier, 2004), quien manifiesta que el proceso de comunicación debe contar con la presencia de los siguientes elementos: emisor, receptor, mensaje, canal, código, retroalimentación, escucha activa y ruido.

Consecuentemente, en los estudios a distancia de las universidades privadas del Municipio Maracaibo del estado Zulia, los elementos que comprenden la comunicación se encuentran presentes en una mediana escala. Cabe destacar, que la presencia de dichos elementos depende de la voluntad de los miembros internos de la dirección, y no incentivar el incremento de su presencia, permite que el proceso de comunicación suceda con una efectividad media. 


\section{Tabla 2}

Distribución de Medias Aritméticas de los Indicadores de la Dimensión Características de las Tecnologías de la Información y la Comunicación de la Variable Tecnologías de la Información y la Comunicación

\begin{tabular}{|l|c|c|c|c|c|c|c|c|}
\hline \multirow{2}{*}{ DIMENSIÓN } & \multicolumn{7}{|c|}{ Características de las Tecnologías de la Información y la } \\
& \multicolumn{7}{|c|}{ Comunicación } \\
\hline INDICADORES & INMATER & INTERC & INTERACTIV & INSTANT & DIGIT & DIVERS & INNOV & MULTIMED \\
\hline$X_{\text {Indicador }}$ & 4,57 & 3,60 & 3,60 & 3,40 & 3,86 & 4,21 & 2,14 & 2,95 \\
\hline$X_{\text {Dimensión }}$ & \multicolumn{70}{|c|}{3.54} \\
\hline
\end{tabular}

En la tabla 2 se observa que la media aritmética del indicador inmaterialidad es de 4.57 ubicándolo en la categoría de alta utilización en atención al baremo establecido. Esto coincide con (Rosario, 2005) quien fundamenta que la inmaterialidad es la falta de materia física durante el manejo de la información. Consecuentemente, los estudios a distancia de las universidades privadas del Municipio Maracaibo del estado Zulia, manejan información de forma inmaterial, es decir, que se utiliza poco material físico, como papeles o libros, y en su lugar, se utilizan datos almacenados en espacios virtuales.

Asimismo, se observa que la media aritmética del indicador interconexión es de 3.60 ubicándolo en la categoría de media utilización en atención al baremo establecido.

Esto se encuentra medianamente en concordancia con lo expuesto por (Cabero, 2007), quien explica que las Tecnologías de la Información y la Comunicación pueden presentarse en forma de diferentes herramientas que pueden combinarse entre sí para construir realidades expresivas y comunicativas. 
Del mismo modo, se observa que la media aritmética del indicador interactividad es de 3.60 ubicándolo en la categoría de media utilización en atención al baremo establecido. Esto coincide medianamente con (Cabero, 2007) quien fundamenta que en la interactividad, las Tecnologías de la Información y la Comunicación posibilitan que el control de la comunicación se desplace del emisor al receptor alternando su rol.

Igualmente, se observa que la media aritmética del indicador instantaneidad es de 3.40 ubicándolo en la categoría de media utilización en atención al baremo establecido.

Esto se encuentra medianamente en concordancia con lo expuesto por (Cabero, 2007) quien indica que las Tecnologías de la Información y la Comunicación poseen la posibilidad de transmitir información en períodos de tiempo mínimos sin importar la distancia física en la que se encuentren.

De igual manera, se observa que la media aritmética del indicador digitalización es de 3.86 ubicándolo en la categoría de alta utilización en atención al baremo establecido. Esto coincide con lo expuesto por (Cabero, 2007) quien explica que la digitalización es la característica que poseen las Tecnologías de la Información y la Comunicación de no ser palpables, y por ende, manipulables, almacenables y transferibles mediante herramientas informáticas.

Asimismo, se observa que la media aritmética del indicador diversidad es de 4.21 ubicándolo en la categoría de alta utilización en atención al baremo establecido. Esto coincide con lo expuesto por (Cabero, 2007) quien explica que las Tecnologías de la Información y la Comunicación se presentan en diferentes formas a disposición de sus usuarios. 
En este mismo orden de ideas, se observa que la media aritmética del indicador innovación es de 2.14 ubicándolo en la categoría de baja utilización en atención al baremo establecido. Esto difiere con lo planteado por (Cabero, 2007) quien manifiesta que, mediante la innovación, la tecnología evoluciona de forma progresiva y rápida.

Estos resultados indican que, los estudios a distancia de las universidades privadas del Municipio Maracaibo del estado Zulia, manejan tecnología con una medida baja de innovación. El uso de las últimas tecnologías tiende a limitarse en el contexto nacional debido a que requieren grandes inversiones para poder ser implementadas, así como también, transferencia tecnológica, cuya deficiencia, causa que las tecnologías empiecen a ser aplicadas en el país mucho tiempo después de que han sido creadas en otra parte o que no sean aplicadas en lo absoluto.

Igualmente, se observa que la media aritmética del indicador multimedialidad es de 2.95 ubicándolo en la categoría de baja utilización en atención al baremo establecido. Esto difiere con lo establecido por (Cabero, 2007) que define multimedialidad como la capacidad de la tecnología de implementar y complementar diferentes formatos en un mismo mensaje.

Finalmente, en relación con la dimensión Características de las Tecnologías de la Información y la Comunicación, se observa que la media aritmética es de 3.54 ubicándola en la categoría de media utilización en atención al baremo establecido. Esto se encuentra medianamente en concordancia con lo expuesto por (Cabero, 2007), quien manifiesta que las Tecnologías de la Información y la Comunicación se encuentran comprendidas por las siguientes características: Inmaterialidad, Interconexión, Interactividad, Instantaneidad, Digitalización, Diversidad, Innovación y Multimedialidad. 
Como consecuencia de esto, las Tecnologías de la Información y la Comunicación en los estudios a distancia de las universidades privadas del Municipio Maracaibo del estado Zulia, presentan las características que las comprenden, sin embargo, el uso de los mismos ocurre en mediana escala, aportando, al proceso de comunicación, una mediana efectividad.

\section{Tabla 3}

Distribución de Medias Aritméticas de los Indicadores de la Dimensión

Condiciones De Los Procesos Mediados Por Las Tecnologías de la Información y la Comunicación de la Variable Tecnologías de la Información y la Comunicación

\begin{tabular}{|l|c|c|c|c|}
\hline \multirow{2}{*}{ DIMENSIÓN } & \multicolumn{5}{|c|}{$\begin{array}{c}\text { Condiciones de los procesos mediados por las } \\
\text { Tecnologías de la Información y la Comunicación }\end{array}$} \\
\hline INDICADORES & $\begin{array}{c}\text { CONDICION } \\
\text { VIRTUAL }\end{array}$ & $\begin{array}{c}\text { CONDICION } \\
\text { INTERACTIVA }\end{array}$ & $\begin{array}{c}\text { CÓNDICION } \\
\text { ASINCRÓNICA }\end{array}$ & $\begin{array}{c}\text { CONDICION } \\
\text { HIPERMEDIATICA }\end{array}$ \\
\hline$X_{\text {Indicador }}$ & 4.60 & 3.95 & 3.50 & 4.17 \\
\hline$X_{\text {Dimensión }}$ & \multicolumn{4}{|c|}{4.05} \\
\hline
\end{tabular}

En la tabla 3 se observa que la media aritmética del indicador condición virtual es de 4.60 ubicándolo en la categoría de alta utilización en atención al baremo establecido. Esto coincide con (Rietveldt y Neuman, 2008) quienes fundamentan la comunicación no ocurre en un espacio físico real; en vez de ello, sucede en un espacio virtual que se encuentra constituido por bits de información y no por átomos.

Por otra parte, se observa que la media aritmética del indicador condición interactiva es de 3.95 ubicándolo en la categoría de alta utilización en atención al baremo establecido. Esto coincide con lo expuesto por (Rietveldt y Neuman, 2008) quienes manifiestan que en los procesos mediados por las Tecnologías de la Información y la Comunicación el 
emisor y el receptor mantienen el flujo bidireccional de información alternando sus funciones dentro del proceso comunicativo.

Asimismo, se observa que la media aritmética del indicador Condición Asincrónica es de 3.50 ubicándolo en la categoría de media utilización en atención al baremo establecido. Esto coincide medianamente con (Rietveldt y Neuman, 2008), quienes plantean que la Condición Asincrónica es aquella que le permite a las Tecnologías de la Información y la Comunicación complementar acciones en tiempos descoordinados.

De igual manera, se observa que la media aritmética del indicador condición hipermediática es de 4.17 ubicándolo en la categoría de alta utilización en atención al baremo establecido. Esto coincide con lo expuesto por (Cely, 2004) quien define a la condición hipermediática como la circunstancia de las Tecnologías de la Información y la Comunicación en la cual se combinan el hipertexto y la multimedia, originando así la combinación de ideas y conceptos.

Finalmente, en relación con la dimensión Condiciones De Los Procesos Mediados Por Las Tecnologías de la Información y la Comunicación, se observa que la media aritmética es de 4.05 ubicándola en la categoría de alta utilización en atención al baremo establecido. Esto se encuentra en concordancia con lo expuesto por (Rietveldt y Neuman, 2008), quienes manifiestan que los procesos mediados por las Tecnologías de la Información y la Comunicación, se encuentran sujetos a ciertas condiciones las cuales son: la virtual, la interactiva, la asincrónica y la hipermediática.

Como consecuencia de esto, en los estudios a distancia de las universidades privadas del Municipio Maracaibo del estado Zulia, se encuentran presentes en una alta escala, las condiciones de los procesos mediados por las Tecnologías de la Información y la Comunicación, aportando una alta efectividad al proceso de comunicación. 
Tabla 4

Distribución de Medias Aritméticas de las Dimensiones de la Variable Tecnologías de la Información y la Comunicación

\begin{tabular}{|l|c|c|c|}
\hline VARIABLE & \multicolumn{3}{|c|}{ Tecnologías de la Información y la Comunicación } \\
\hline DIMENSIONES & $\begin{array}{c}\text { ELEMENTOS } \\
\text { ESTRUCTURALES } \\
\text { DE LA } \\
\text { COMUNICACIÓN }\end{array}$ & $\begin{array}{c}\text { CAS TECNOLOGÍAS DE LA } \\
\text { INFORMACIÓN Y LA } \\
\text { COMUNICACIÓN }\end{array}$ & $\begin{array}{c}\text { CONDICIONES DE } \\
\text { LOS PROCESOS } \\
\text { MEDIADOS POR LAS } \\
\text { INFORMACIÓN DE LA LA } \\
\text { COMUNICACIÓN }\end{array}$ \\
\hline $\mathbf{X}_{\text {dimensiones }}$ & 3.64 & 3.54 & 4.05 \\
\hline $\mathbf{X}_{\text {variable }}$ & \multicolumn{3}{|c|}{3.74} \\
\hline
\end{tabular}

Adicionalmente, en la tabla 4, en relación a la variable tecnologías de la información y comunicación, se observa que la media aritmética es de 3,74 ubicándola en la categoría alta utilización en atención al baremo establecido. Esto concuerda con lo establecido por (Rosario, 2005) quien indica que mediante las mismas es posible la "adquisición, producción, almacenamiento, tratamiento, comunicación, registro y presentación de informaciones, en forma de voz, imágenes y datos". Estos resultados indican que los estudios a distancia de las universidades privadas del Municipio Maracaibo del estado Zulia utilizan las tecnologías de la información y comunicación para manejar información en su proceso comunicativo.

\section{LINEAMIENTOS}

Por último, los resultados arrojados permitieron generar lineamientos para la optimización del uso de las Tecnologías de la Información y la Comunicación utilizadas en los estudios a distancia de las universidades privadas del Municipio Maracaibo, estos son los siguientes: 
1. Se debe fomentar la realización de dinámicas que impliquen el uso de videollamadas, llamadas en conferencia y la voz sobre I.P., mediante las cuales se podrá apreciar la presencia del elemento escucha activa, así como también, aprovechar con más amplitud los diversos canales a los cuales se tiene acceso mediante la tecnología.

2. Se debe verificar el software interactivo actualmente utilizado (Moodle), indagar entre las herramientas que posee y determinar, entre aquellas que tienen poco uso, cuales poseen ventajas que no estén siendo aprovechadas para así aprovecharlas. Así como también, fomentar el uso de la herramienta "Pizarra compartida". De esta manera, todos los individuos podrán, eventualmente, tener control sobre la forma en la cual recibe la comunicación

3. Se debe expandir la capacidad de los servidores para disminuir los inconvenientes técnicos y la eventual presencia de lentitud y fallas de sistema, del mismo modo, acelerar los tiempos de transmisión y agregar instantaneidad al proceso comunicativo.

4. Se debe indagar en los últimos avances tecnológicos, investigar su aplicabilidad en los estudios a distancia y determinar las ventajas que puede ofrecer, para así concluir si es conveniente invertir en su exportación y adquisición. De esta manera, estudiar la posibilidad de aplicar la tecnología de "realidad aumentada" en los estudios a distancia, ya que mediante la innovación de las tecnologías aumenta considerablemente la efectividad en el proceso comunicativo.

\section{CONCLUSIONES}

Una vez realizado el análisis y la discusión de los resultados, y en atención a los objetivos establecidos para la presente investigación se logró concluir lo siguiente:

En relación con el primer objetivo planteado, se identificaron los elementos estructurales de la comunicación considerados en los estudios a distancia de las 
universidades privadas del Municipio Maracaibo, concluyendo que existe una destacada utilización de el código, el receptor, la retroalimentación y el mensaje, una presencia considerable del emisor y del canal y un poco uso de la escucha activa y el ruido dentro del proceso de comunicación.

Cabe destacar que estos elementos estructurales representados por los individuos dentro del proceso y las tecnologías utilizadas, se integran suficientemente para que no surjan inconvenientes durante la circulación de información, más allá del uso mediano de los canales de comunicación disponibles y la presencia mínima de la escucha activa, debido a la existencia de ciertos paradigmas comunicacionales. Como se acostumbra a que, mediante estas tecnologías, no es necesaria la visualización de los individuos, sólo se puede apreciar escucha activa en la interpretación y lectura de información escrita, a pesar de que estas herramientas lo permiten sin mayor dificultad, y esto desaprovecha el potencial comunicacional.

Con respecto al segundo objetivo específico, se describieron las características de las tecnologías de la información y la comunicación utilizadas en los estudios a distancia de las universidades privadas del Municipio Maracaibo, concluyendo que las mismas tecnologías perfilan la manera en la cual pueden ser utilizadas, tomando en cuenta que, en los estudios anteriormente mencionados, son las herramientas básicas, y prácticamente, las únicas mediante las cuales se establece la comunicación.

En ellas, existe una leve falta en la presencia de ciertas características, ya que se demostraron niveles medios de interconexión, interactividad, e instantaneidad. En una parte importante existe dependencia de rendimiento tecnológico, lo cual incide en dichos elementos hasta un determinado nivel. Por otra parte, la falta de innovación se fundamenta en la lentitud con las cuales las nuevas tecnologías ingresan al país, 
causado por un contexto económico nacional deficiente, que ralentiza la asimilación de tecnología nueva, dejando los últimos avances fuera del alcance de las universidades.

En lo que respecta al tercer objetivo, se analizaron las condiciones de los procesos mediados por las Tecnologías de la Información y la Comunicación aplicadas en los estudios a distancia de las universidades privadas del Municipio Maracaibo, y se concluyó que, en efecto, los estudios a los cuales se hace referencia, están condicionados por determinados elementos, por ser un proceso que depende de estas tecnologías. Asimismo, siempre y cuando exista una presencia suficiente de virtualidad, interactividad, asincronía y elementos hipermediáticos, la comunicación será, altamente efectiva.

En relación con el cuarto objetivo, se propusieron lineamientos para la optimización de las Tecnologías de la Información y la Comunicación utilizadas en los estudios a distancia de las universidades privadas del Municipio Maracaibo, en función de corregir las deficiencias detectadas y mejorar el proceso de comunicación.

Con respecto al objetivo general, se analizaron las Tecnologías de la Información y la Comunicación utilizadas en los estudios a distancia de las universidades del Municipio Maracaibo, concluyendo que a través de los elementos estructurales utilizados se garantiza un efectivo proceso comunicacional. A su vez, el éxito de este tipo de estudios se fundamenta en un proceso comunicativo eficiente, efectivo y oportuno gracias a la alta presencia de características como la inmaterialidad, la digitalización, la interconexión y la interactividad, entre otras.

Asimismo, este proceso se apalanca en condiciones como virtualidad, interactividad, asincronía e hipermediaticidad. Todo ello permite que los estudios, a los cuales se hace referencia, se desarrollen sin inconvenientes significativos, pero a su vez, detectando 
leves deficiencias que pueden ser corregidas en función de aprovechar el potencial comunicativo de las mismas.

\section{BIBLIOGRAFÍA}

- ALARICO, C.: "Lenguaje y Comunicación". Caracas, 2001. Panapo.

- CABERO, J.: "Nuevas Tecnologías, Comunicación y Educación" 2002. [Documento en línea]. Disponible: http://tecnologiaedu.us.es/ bibliovir/pdf/3.pdf [Consulta: 2010, junio 19].

- CABERO, J. LlORENTE, M. y ROMÁN, P.: “Las Herramientas de Comunicación en el Aprendizaje Mezclado" 2004. [Documento en línea]. Disponible: http://www.lmi.ub.es/te/any2004/documentacion/3_cabero. pdf [Consulta: 2010, junio 19].

- CABERO, J.: "Nuevas Tecnologías aplicadas a la Educación". Madrid, 2007. McGraw Hill.

- CAMARGO, X.: "La Orientación Comunitaria y las Herramientas Comunicacionales para su Abordaje. Un Enfoque Social de la Orientación". 2008. [Documento en línea]. Disponible: $\quad$ http:// pepsic.bvs-psi.org.br/pdf/remo/v6n16/v6n16a06.pdf [Consulta: 2010, junio 19].

- CASCÓN, P.: "Educar en y para el Conflicto". 2004. [Documento en línea]. Disponible: http://www.edualter.org/material/denip2004/herramientas. htm [Consulta: 2010, junio 19].

- CELY, A.: "Cibergrafía: Propuesta teórico metodológica para el estudio de los medios de comunicación social cibernéticos". 2004 [Documento en línea]. http://redalyc.uaemex.mx/redalyc/html/ 310/31004306/31004306.html [Consulta: 2010, junio 19].

- CURSI LA ROCCA, R.: "Diagnóstico de la Educación Superior Virtual en Venezuela". 2003. [Documento en línea]. Disponible: 
http://www.ruvae.edu.ve/unesco/UNESCO_EDUCACIONVIRTUAL_VENEZU ELA.pdf [Consulta: 2010, junio 19].

- GARCÍA, L. DOMINGUEZ, D. y RUIZ, M.: “De la Educación a distancia a la educación virtual". 2007. Barcelona: [Documento en línea]. Disponible: http:/ / books.google.co.ve/books?id=d2MBPSVViEgC\&pg=PA98\&dq=COMUNI CACION+VIRTUAL+EN+EDUCACION+A+DISTANCIA\&hl=es\&ei=fcbUTMOY D4GC8gaO4_WiCg\&sa=X\&oi=book_result\&ct=result\&resnum=1\&ved=0CC8Q6A EwAA\# $\mathrm{v}=$ onepage\& $\mathrm{q} \& \mathrm{f}=$ false [Consulta: 2010, junio 19].

- FOURNIER, C.: “Comunicación Verbal”. 2004 [Documento en línea]. Disponible: http:// books.google.co.ve/books?id=YlgniEnyRGwC\& printsec $=$ frontcover\&source $=g b s \_g e \_s u m m a r y \_r \& c a d=0 \# v=$ onepage \&q\&f=false [Consulta: 2010, junio 19].

- HeRAS, L. y VILlareAL, J.: "La Realidad Aumentada: una tecnología en espera de usuarios". 2004. [Documento en línea]. Disponible: http://www.revista.unam.mx/vol.8/num6/art48/jun_art48.pdf [Consulta: 2010, junio 19].

- OBSERVATORIO PARA LA SOCIEDAD DE LA INFORMACIÓN EN LATINOAMÉRICA Y EL CARIBE (OSILAC).: "El estado de las estadísticas sobre Sociedad de la Información en los Institutos Nacionales de Estadística de América Latina y el Caribe". 2004. [Documento en línea]. Disponible: http://www.itu.int/wsis/stocktaking/docs/activities/1102712635/statisticses.pdf [Consulta: 2010, junio 19].

- RIETVELD DE ARTEAGA, F. y NEUMAN, M.: “Estrategias y Nuevas Tecnologías en Educación". Maracaibo, 2008. Universidad Rafael Belloso Chacín.

- ROSARIO, J.: “La Tecnología de la Información y la Comunicación (TIC). Su uso como Herramienta para el Fortalecimiento y el Desarrollo de la Educación Virtual". 2005 [Documento en línea]. Disponible: http://www.cibersociedad.net/ archivo/articulo.php?art=218 [Consulta: 2010, junio 19]. 
- STOKES, H. "La Interactividad en la Educación a Distancia: Evaluación de Comunidades de Aprendizaje". 2004 [Documento en línea]. Disponible: http://www.utpl.edu.ec/ried/images/pdfs/vol7-1-2/la_interactividad.pdf [Consulta: 2010, junio 19].

- VAN-DER HOFSTADT, C.: "El Libro de las habilidades de comunicación. Como mejorar la comunicación personal". 2005. [Documento en línea]. Disponible: http:/ / books.google.co.ve/ books?id=7ldQbFzhRBkC\&pg= PA78\&dq=elemento+comunicaci\%C3\%B3n+escucha+activa\&hl=es\&ei=LwMkTOi RIoP-8AapkMn6Dw\&sa=X\&oi=book_result\&ct=result\&resn

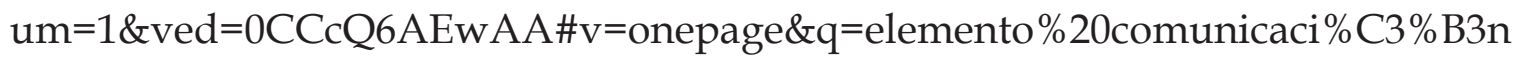
$\% 20$ escucha \%20activa\&f=false [Consulta: 2010, junio 19].

- VIGNOLLES, M.: La Comunicación Asincrónica en Educación a Distancia. Barcelona, 2006. Paidós. 